\title{
Final thermomechanical treatment of thin NiTi filaments for textile applications by electric current
}

\author{
J. Pilch ${ }^{\mathrm{a}}$, L. Heller and P. Sittner \\ Institute of Physics of the ASCR, Prague, Czech Republic
}

\begin{abstract}
Functional properties of NiTi filaments can be in a large extent controlled by the heat treatment after final cold drawing. Conventionally, this is being performed by straight annealing in long tubular electrical furnace by SMA providers. An alternative heat treatment method by Joule heating called Final Thermomechanical Treatment by Electric Current /FTMT-EC/ is presented in this work. Results of key experiments performed while developing the method are discussed in this paper. A prototype of a compact device for FTMT-EC treatment of continuous NiTi filaments is presented and differences compared to the conventional heat treatment in a furnace are discussed.
\end{abstract}

\section{Introduction}

Shape memory alloys (SMA) have attracted considerable attention for their unique thermomechanical properties deriving from the martensitic transformation (MT) in solid state. Among them, the near equiatomic Ni-Ti alloy is the most popular, practically important and has been most thoroughly investigated. Ni-Ti wires, sheets, tubes for engineering applications are produced from extruded semiproducts by multiple hot working passes finished by a final cold working pass. In this so called "cold worked" (as drawn, hard, etc.) state, the alloy posses a heavily deformed microstructure [1-4] consisting of mixture of austenite, martensite, and amorphous phase with defects and internal stress. Since the NiTi alloy in this state does not show any functional property, it needs to be subjected to a "final heat treatment" which converts the as drawn microstructure into an annealed microstructure in which it exhibits the desired functional properties. At the same time, if the shape of a SMA element is constrained during this final heat treatment, this shape becomes its new "parent shape" in high temperature phase. Since the constraint provides mechanical action during the heating/cooling, the final heat treatment is thus in fact a "final thermomechanical treatment".

The heat treatment is performed either by SMA producers - in special case of continuous as drawn Ni-Ti wires by a process called "straight annealing" or by the engineers who heat treat short NiTi wires in various fixtures in order to give then required shape while developing $\mathrm{Ni}$-Ti applications (e.g. production of $\mathrm{Ni}-\mathrm{Ti}$ springs or braided superelastic stents involving shape setting of Ni-Ti wires into helical shapes). Straight annealing treatment of $\mathrm{Ni}-\mathrm{Ti}$ wires is a just special case of shape setting treatment in which a low constant force $\sim 20 \mathrm{MPa}$ representing the applied constraint is applied during the heat treatment. The effect of the heat treatment temperature and time on the martensitic transformations of $\mathrm{Ni}-\mathrm{Ti}$, particularly transformation sequences and temperatures as well as on the functional mechanical properties has been thoroughly investigated in the literature $[5,6]$. This now seems to be relatively well understood at least for the Ni-rich Ni-Ti alloys commonly used to manufacture the superelastic medical Ni-Ti wires. According to the current state of art, the mechanical as well as functional properties of $\mathrm{Ni}-\mathrm{Ti}$ wires (transformation temperatures, stresses, strains, yield stress, strength, ductility, cyclic deformation properties etc.) can be set $[5,6]$ by employing proper combination of:

- $\quad$ selection of alloy composition

- hot working/annealing texture forming process

- amount of the cold work performed in the last wire drawing step,

- temperature of the heat treatment,

- time of heat treatment

- type of constraint applied during the heat treatment.

${ }^{a}$ e-mail: pilch@fzu.cz

This is an Open Access article distributed under the terms of the Creative Commons Attribution-Noncommercial License (http://creativecommons.org/licenses/by-nc/3.0/), which permits unrestricted use, distribution, and reproduction in any noncommercial medium, provided the original work is properly cited. 
Depending on the alloy (chemical composition, cold work), conventional heat treatment conditions leading to best results can be found in the range of temperatures $400^{\circ} \mathrm{C}-500^{\circ} \mathrm{C}$ and time $10-60$ minutes. Less known is the role of the mechanical constraint applied during the shape setting. It probably does affect the functional behaviors as suggested for example by Favier and al. [7] for the case of thin wall Ni-Ti tubes for stent production. This is also why the tensile force applied during the straight annealing treatment of superelastic $\mathrm{Ni}$ $\mathrm{Ti}$ wires is a very important technological parameter of the Ni-Ti wire production process. Another less known aspect of the shape setting technology is the influence of the heat treatment parameters on the quality of the shape setting achieved by the heat treatment.

Recently, the necessity to expose the NiTi wire to high temperatures for several minutes while performing the heat treatment have started to pose problems for emerging technology of NiTi textiles [8]. First one would like to heat treat the wires already integrated in textiles made of filaments which burn at $250^{\circ} \mathrm{C}$ so that it is not possible to put them into furnace. There is also a need to heat treat kilometers of continuous NiTi thin filaments in a laboratory or on a textile compatible equipment at textile producer premises while weaving or knitting with NiTi filaments. Maximum respooling speed of $\sim 1 \mathrm{~m} / \mathrm{min}$ achievable with conventional tubular electrical furnaces is painfully slow for this purpose. To solve this problem we have investigated the possibility to treat continuous long thin Ni-Ti filaments by passing electric current through it during respooling as an alternative method to the conventional straight annealing treatment in tubular electrical furnace. The method has been called "Final Thermo Mechanical Treatment by Electric Current" /FTMT-EC/[2, 9].

\section{Heat treatment of short wires by pulsed electric current}

Heat treatment experiments were carried out using a miniature deformation rig MITTER developed purposely for efficient testing of functional thermomechanical properties of thin Ni-Ti filaments in tension. The MITTER rig consists of a stepping motor, $100 \mathrm{~N}$ load cell, electrically isolated grips, Peltier furnace, laser micrometer for strain measurement and special electronics allowing to send controlled electric power pulse to heat the $\mathrm{Ni}-\mathrm{Ti}$ wire up to the melting point and perform simultaneously electric resistance measurement.

All shape setting experiments were performed on Fort Wayne Metals \#1 superelastic as drawn Ni-Ti wire ( $56.0 \mathrm{wt} . \% \mathrm{Ni}$ ) having diameter $\mathrm{d}=0.1 \mathrm{~mm}$. The wire is first mounted on the rig. After the initial length $1_{0}(\sim 50$ $\mathrm{mm}$ ) and initial electrical resistance of the wire $\rho_{0}$ at room temperature are evaluated, the wire is preloaded to a desired tensile stress (e.g. $400 \mathrm{MPa}$ in present experiments) and its length is fixed. Following that, while the legth is kept constant, the wire is exposed to a controlled DC power pulse characterized by maximum power $\mathrm{P}$ $\left(\mathrm{P}_{-} \mathrm{HIGH}\right)$ and additional 7 parameters $\mathrm{P}_{\mathrm{LOW} \_0}, \mathrm{P}_{\mathrm{LOW} \_1}, \mathrm{t} \_01, \mathrm{t} \_1, \mathrm{t} \_2, \mathrm{t} \_3, \mathrm{t} \_02$ (Fig. 1a). It is essential that the electronics system is capable of controlling the desired $\mathrm{P}(\mathrm{t})$ pulse profile even if the electric resistance of the wire drastically changes during the Joule heating event. Roughly, two parameters $\mathrm{P}, \mathrm{t} \_2$ are sufficient to describe the temperature history $\mathrm{T}=\mathrm{T}(\mathrm{t})$ the wire is exposed to. Temperature of the wire is calculated (Fig. 1b) according to Equation 1 taking into account the Joule heat supply and temperature losses into the air environment.

$$
\frac{d}{d t}\left(T_{p}(t) \cdot C\right)=P-h \cdot K_{1,2} \cdot\left(T_{p}(t)-T_{e x t}\right) T_{p}(0)
$$

The heat capacity $\mathrm{C}$ is assumed to be temperature independent. The specific heat transfer coefficients $\mathrm{K}_{1,2}$ describing the heat dissipation into the air are assumed to be constant. In fact best results were achieved with two coefficients $\mathrm{K}_{1}$ and $\mathrm{K}_{2}$ used in low $\left(<400^{\circ} \mathrm{C}\right)$ and high $\left(>400^{\circ} \mathrm{C}\right)$ temperature regimes. In the calculation, latent heat of the phase transformations as well as heats dissipated by the exothermic reactions due to lattice recovery processes are neglected since we assume that the Joule heat dominates. Heat loss due to convection is neglected due to filament geometry. Homogeneous distribution of temperature in the wire is assumed. The equation (1) does not hold for heating near the melting point $1300^{\circ} \mathrm{C}$ due to the absence of the latent heat of fusion.
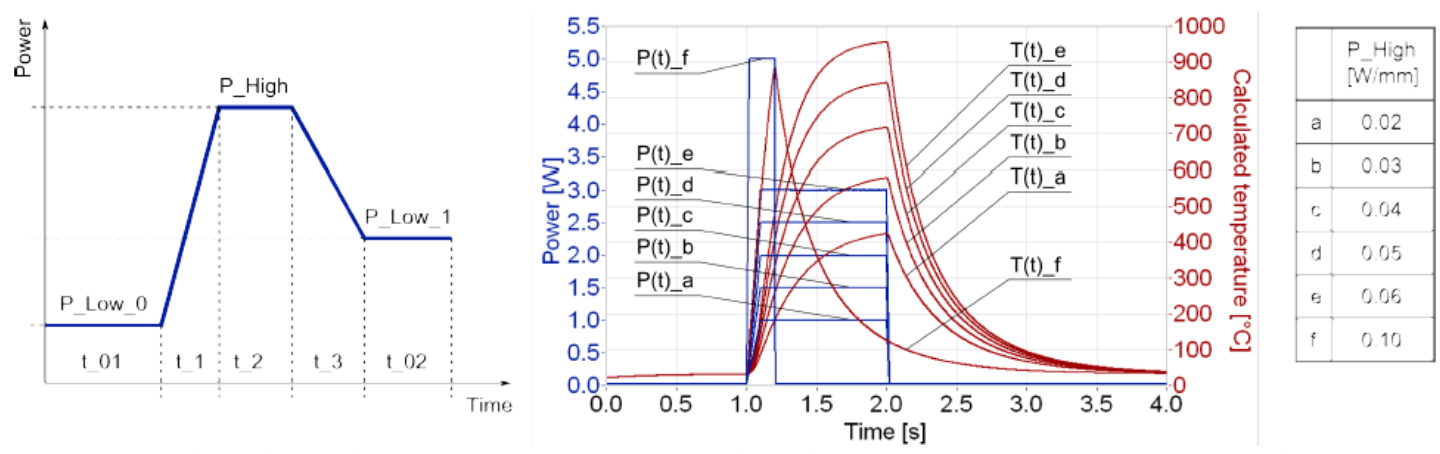

Fig. 1: 6 parameters describing the DC power pulse applied in the FTMT-EC treatment (left) and temperature profiles $\mathrm{T}=\mathrm{T}(\mathrm{t})$ achieved in $\mathrm{DC}$ pulses with parameters $\mathrm{P} / \mathrm{t}_{2}=2-6 \mathrm{~W} / 1 \mathrm{~s}$ and $10 \mathrm{~W} / 0.2 \mathrm{~s}$ 
a)
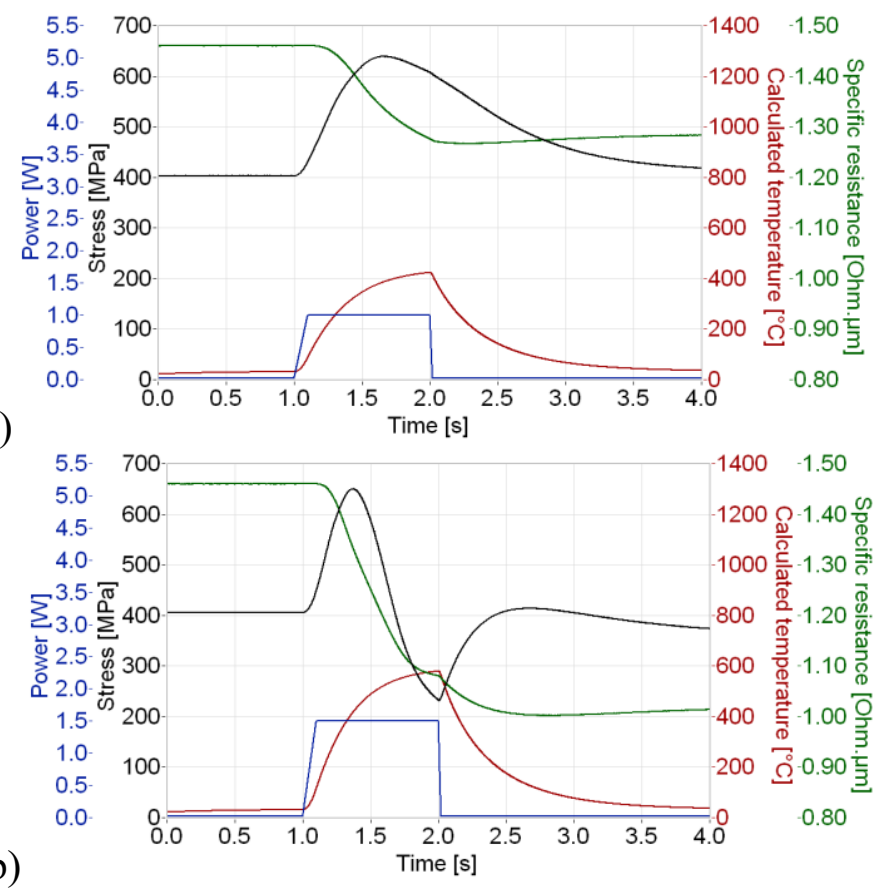

b)

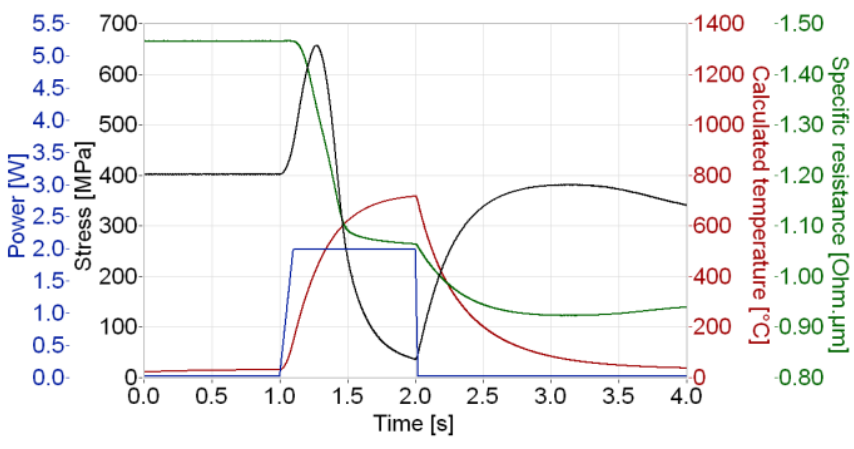

c)

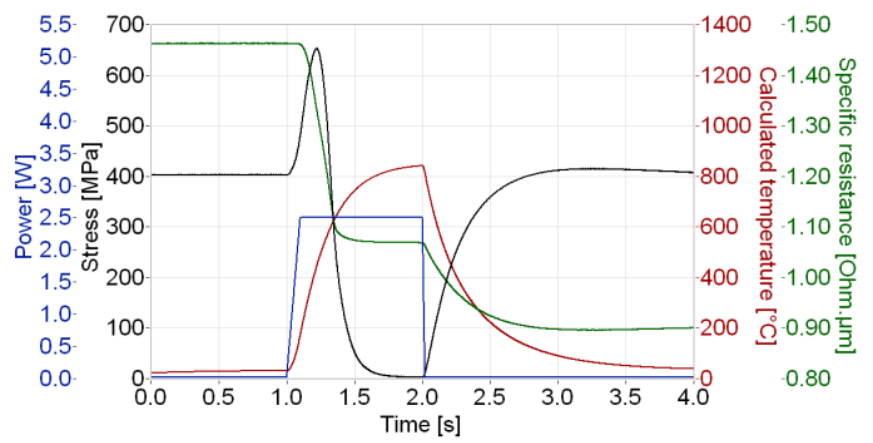

d)

e)

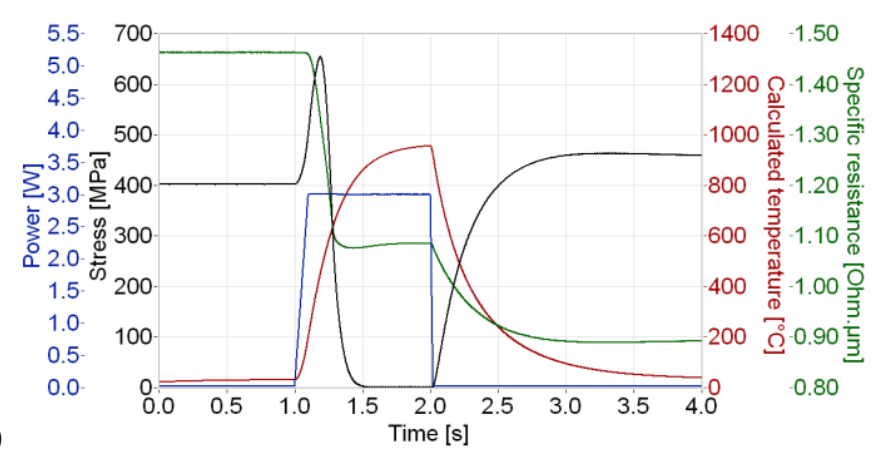

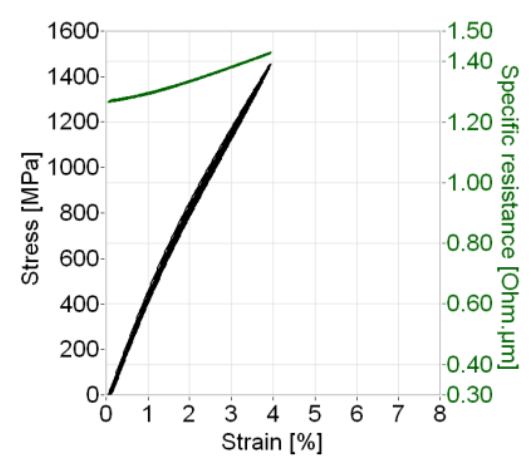
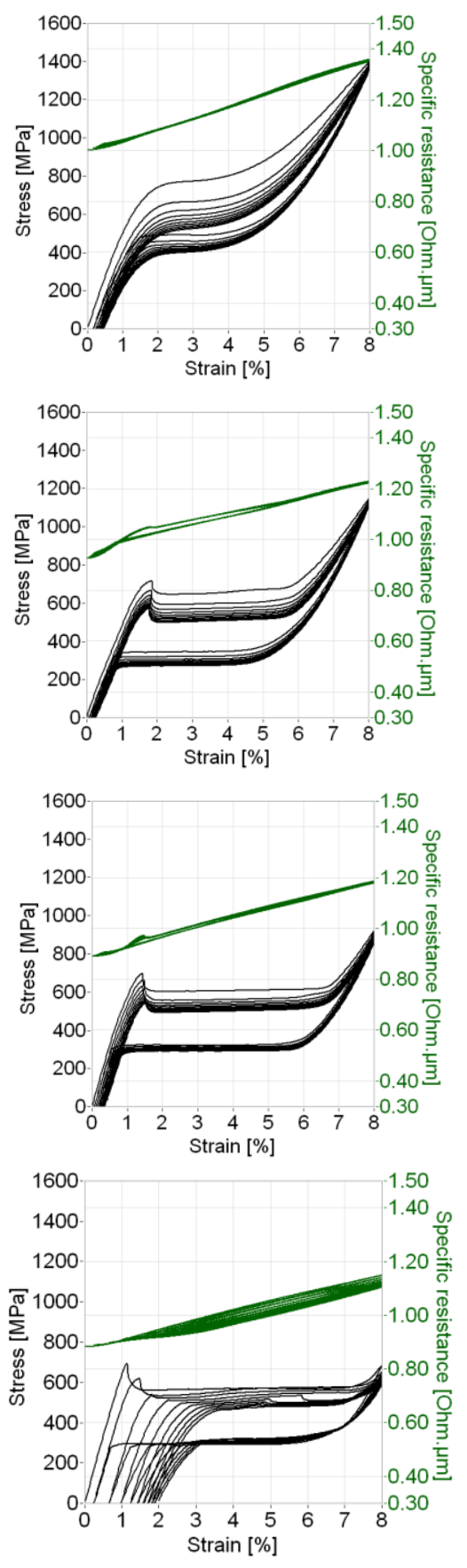

Fig. 2. Evolution of power, temperature, tensile stress and electric resistance of the NiTi wires treated in FTMT-EC treatments with maximum power $\mathrm{P}=2,3,4,5,6 \mathrm{~W} / 100 \mathrm{~mm}$ (left) and corresponding superelastic responses and electric resistivity records of the treated wires (right). 
As the temperature of the wire increases due to the supplied heat (Fig. 1), various thermally activated recovery processes in the heavily cold worked microstructure of the wire are subsequently triggered, proceed and terminate as observed by TEM [3] and in-situ synchrotron X-ray studies [4] carried out in parallel. In response to the recovery processes, the electric resistance of the wire and macroscopic tensile force change dramatically. The recovery processes change the wire microstructure and consequently its functional and mechanical properties. Hence, if we want to control the microstructure, we need to control the progress of the recovery processes during the fast heating. The evolutions of electrical resistivity and stress measured in-situ during the electric power pulse provide information on it. After the treatment is finished, superelastic response of the treated wire in 10 cycles followed by final stretching till fracture at room temperature is evaluated using the same MITTER rig. The obtained superelastic stress-strain curves serve as a figure of merit for the heat setting of functional properties of the treated wires.

A set of heat treatment experiments was performed using different power $P=2-7 \mathrm{~W}$ and time $t_{2}=1 \mathrm{~s}$. Since wires $\sim 50 \mathrm{~mm}$ and $\sim 100 \mathrm{~mm}$ were used in the experiments, the further used values of electric power are normalized on $100 \mathrm{~mm}$ length of the wire. The results of selected experiments are shown in figure 2 . Left side figures show the variation of power, temperature, tensile stress and electric resistivity recorded during the FTMT-EC pulse. Right side figures show the resulting superelastic stress-strain response with superimposed variation of the electric resistivity of the wire. Superelastic responses of the wire achieved by 17 different FTMT-EC treatments are mutually compared in figure 3. The in-situ records of tensile stress and electrical resistivity taken during the individual heat treatments are mutually compared in figure 4 .

Let us briefly explain what is behind the observed evolution of tensile stress and electric resistivity during individual FTMT-EC treatments in figure 2. The tensile stress of a prestrained wire which is heated should normally decrease with increasing temperature due to thermal expansion and thermal dependence of elastic modulus. In the present case, however, the stress starts to increase with increasing temperature right after the onset of heating in all cases (Figs. 2,4). This is due to small fraction of martensite phase and related internal stresses frozen in the heavily cold worked microstructure of the as drawn NiTi wire [2,3] which tend to retransform back to the austenite phase upon heating and shorten the wire. Free NiTi wire heated by any of the pulses $\mathrm{P}>3 \mathrm{~W} / 1 \mathrm{~s}$ becomes $3.3 \%$ shorter after treatment. The tensile stress increases with the increasing temperature (Fig. 4) only up to $450^{\circ} \mathrm{C}$, where it reaches a maximum at $\sim 650 \mathrm{MPa}$. We know from separate insitu $\mathrm{X}$ ray studies [2] that internal stresses become annealed out around this temperature range. Upon further heating, the tensile stress decreases basically down to zero if the supplied power is sufficient to reach high enough temperature (Fig. 4a). The stress decreases due to due to thermal expansion, decrease of elastic modulus and plastic deformation induced at high temperature by the tensile stress. Upon cooling back, the stress linearly increases due to thermal contraction and modulus change. Exception is the $2 \mathrm{~W} / 1 \mathrm{~s}$ treatment in which the residual stresses were not yet completely anneal out, which causes the tensile stress to decrease upon cooling. Tensile stress also decreases upon cooling in $\mathrm{P}=4 \mathrm{~W} / 1 \mathrm{~s}$ treatment at lowest temperatures below $100^{\circ} \mathrm{C}$. This is due to the B2-R transformation taking place in the already heat treated alloy. Though there are minor differences, the original tensile stress $400 \mathrm{MPa}$ is nearly restored after all treatments suggesting that, in the first approximation, the length of the wire did not change.

The electric resistivity of a wire should normally increase with increasing temperature. Indeed if an already fully heat treated NiTi wire is subjected to FTMT-EC pulse, the electric resistivity increases with increasing temperature [2] and fully recovers after cooling back. In present experiments, however, it starts to decrease when the temperature reaches $\sim 200^{\circ} \mathrm{C}$ in all cases (Figs. 2,4) and decreases monotonically till either the peak temperature is reached or till it drops down to $\sim 75 \%$ of its starting value. This happens in temperature range 550 ${ }^{\circ} \mathrm{C}-\sim 700^{\circ} \mathrm{C}$ - see the knee points on the electric resistivity - temperature curves (Fig. 4)). Upon heating beyond the knee point, the electrical resistivity remains nearly constant or even slightly increases. Upon cooling back, the electrical resistivity tends to decrease due to intrinsic thermal dependence of an electric resistivity of a metal (Fig. 4). The unusual increase of electrical resistivity upon cooling at lowest temperatures $(\mathrm{P}=4 \mathrm{~W})$ is due to the already mentioned B2-R phase transformation. The electrical resistivity is not restored after the heat treatment since the microstructure changes are not reversible. Comparing the values before and after treatments, we find out that there is a kind of drop down capacity for the electric resistivity of about $\sim 40 \%$. Major decrease of the electric resistivity occurs in the temperature range $200^{\circ} \mathrm{C}-550^{\circ} \mathrm{C}\left(700^{\circ} \mathrm{C}\right)$. The nanograin microstructures in which the wires show superelastic properties [2,3] are thus created by the subsequent activation of several recovery processes [4] in this temperature range.

It is clear from figures 2,3 that the functional and mechanical properties of this superelastic NiTi wire can be in large extent adjusted by the FTMT-EC treatment, particularly to transformation strain, hysteresis width, unrecovered strain and strength. It is essential that the parameters in figure $3 \mathrm{c}$ were evaluated from the stabilized superelastic curves not from the first one. In present case they were evaluated from the last 13th cycle after which the wire was loaded till fracture (Fig. 3b). Since the time the wire is exposed to high temperature (Figs. $1,2)$ is rather short $(\sim 1 \mathrm{~s})$, we do not expect any change of the composition the B2 matrix taking place during the heat treatment. Useful superelastic properties of the wire as well as shape setting are achieved by FTMT-EC 
treatments using $\mathrm{P}=3-6 \mathrm{~W} / 1 \mathrm{~s}(550 \mathrm{oC}-950 \mathrm{oC})$. Based on the results in figure 3, one can perform an optimized FTMT-EC treatment for particular superelastic performance by selecting proper parameters of the electric pulse (Fig. 1) and constraint.

a)

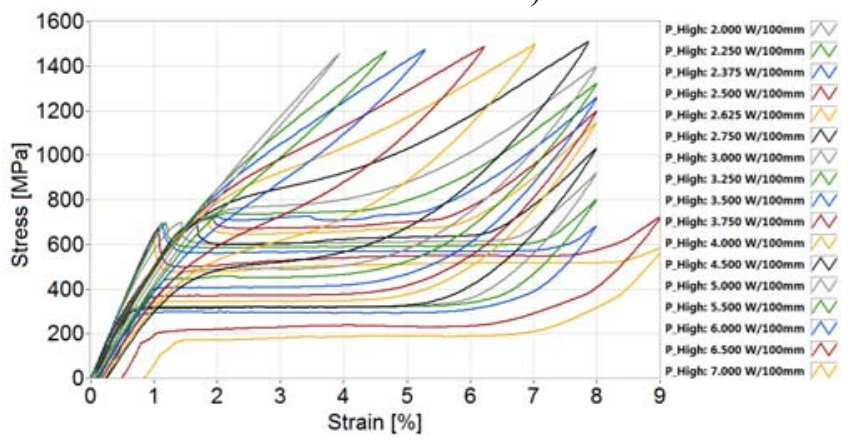

c)

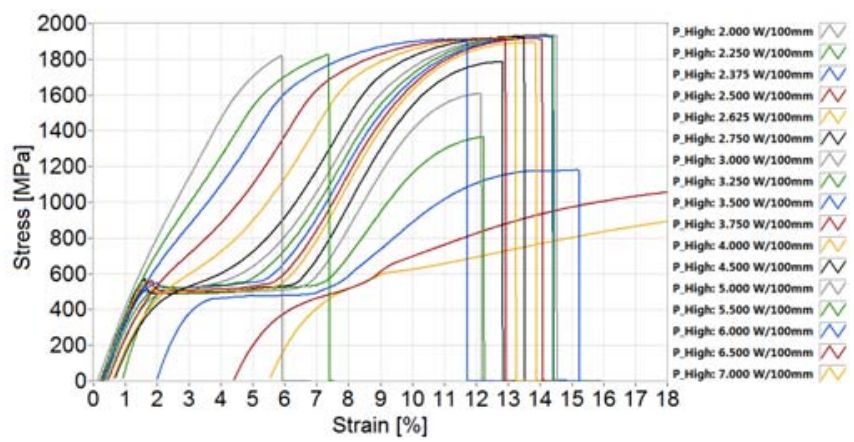

b)

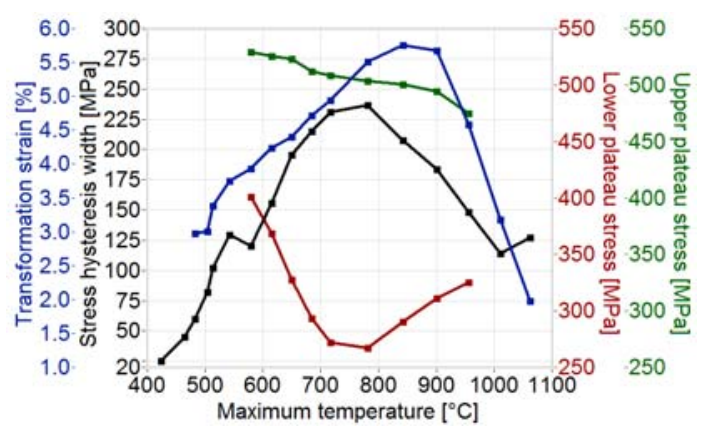

d)

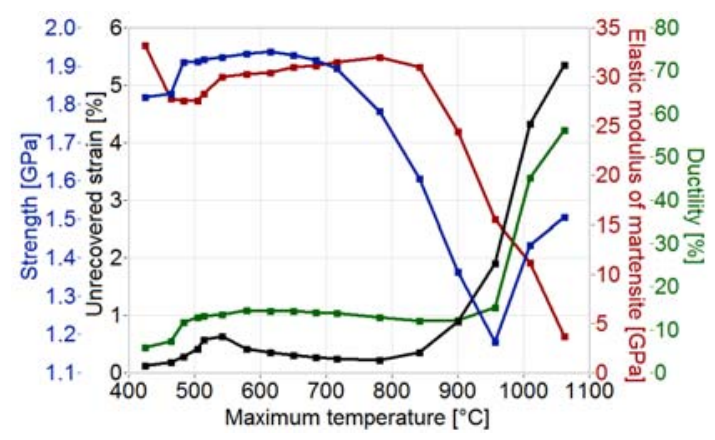

Fig. 3. Superelastic stress-strain curves of the FTMT-EC treated NiTi wires - $P=2-7 \mathrm{~W} / 1 \mathrm{~s}$ (left) and the characteristics determined from 13th superelastic cycle (right) - transformation strain, stress hysteresis width, upper plateau stress, lower plateau stress (upper) and strength, unrecovered strain, ductility, and apparent elastic modulus of martensite in dependence on the maximum temperature reached in the heat treatment pulse.

In order to be able to interpret the experimentally measured evolutions of stress and electrical resistivity during the heat treatments in terms of the activity of recovery processes during the heat pulse we have performed in-situ synchrotron X-ray studies during the treatments [2,4] and ex-situ HRTEM [3] studies of the microstructures in the treated wires. The reader is referred to original papers concerning details of microstructures and recovery processes, let us only point out here that the evolutions of stress and electric resistivity presented in figures 2,4 are not affected only by the irreversible microstructure changes but also by the conventional i) thermal expansion, ii) thermal dependence of electrical resistivity and iii) thermal dependence of elastic modulus which are all essentially reversible and linear with temperature in the first approximation. They can be subtracted from the experimental responses in figure 4 to obtain unbiased evidence on the responses due to recovery processes.

Let us look again on the temperature profiles $\mathrm{T}=\mathrm{T}(\mathrm{t})$ achieved in the FTMT-EC experiments (Figs. 1,2). While temperature and time parameters characterize very well the relatively long time conventional heat treatments, the short time FTMT-EC treatment is characterized by its thermal history $\mathrm{T}(\mathrm{t})$ controlled by the parameters of the electric pulse $\mathrm{P}$ and $\mathrm{t}_{2}$. Since the heat comes from inside the wire during the Joule heating and the heat loss into the environment can be predicted, one can precisely control the supply of heat to the wire at required temperatures in very short time. At the same time, it is possible to control the stress profile $\sigma(\mathrm{t})$ in the treated filament through careful selection of the applied constraint. In this way (by controlling the $\mathrm{T}(\mathrm{t})$ and $\sigma(\mathrm{t})$, the FTMT method [9] allows to control the progress of individual recovery processes during fast heating in such a way that desired microstructure (functional properties) in the wire are obtained.

When adjusting the $\mathrm{T}(\mathrm{t})$ profile for the FTMT-EC treatment one can use various combinations of electric pulse parameters $\mathrm{P}$ and $\mathrm{t}_{2}$. This is important since two pulses yielding same maximum temperature are not necessarily equivalent in their effects on the recovery processes and microstructure changes. One can even use more complex electric current pulses or pulse sequences [2]. It is essential to control precisely the air environment of the treated wire (controlled $T_{\text {ext }}$, controlled air flow) otherwise the Eq. 1 yields wrong $T(t)$ results. Given the requirement for precise control of $\mathrm{T}(\mathrm{t})$ by Joule heating and large variation of the electric resistance of the wire during the treatment, it is essential that the electronics system is capable of controlling the supplied electric power precisely in time (Figs. 1,2). If this is fulfilled, the thermal history $\mathrm{T}(\mathrm{t})$ of the treatment can be perfectly reproduced and wires with required properties can be obtained. Nevertheless, maximum 
temperature reached in the heat pulse can be used as a first guide. Similar functional properties were obtained in FTMT-EC treatments $5 \mathrm{~W} / 1 \mathrm{~s}, 10 \mathrm{~W} / 0.2 \mathrm{~s}$ (Fig. 1) and $125 \mathrm{~W} / 0.012 \mathrm{~s}$ [2] in which temperature $\sim 900^{\circ} \mathrm{C}$ is reached.

a)

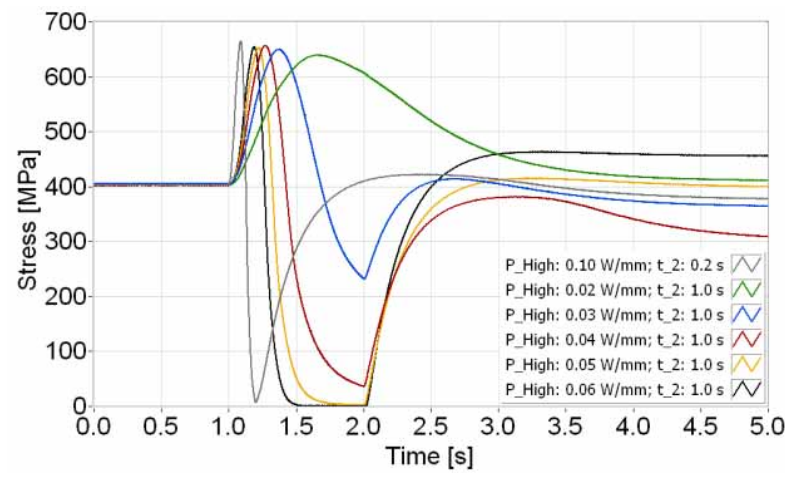

c)

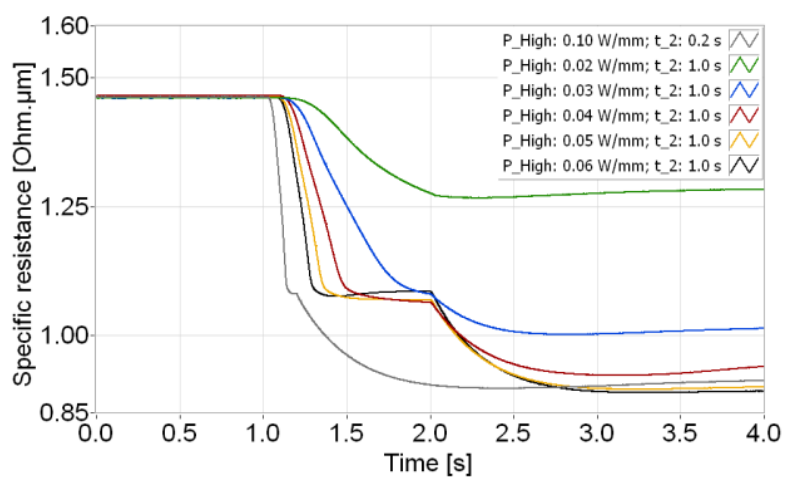

b)

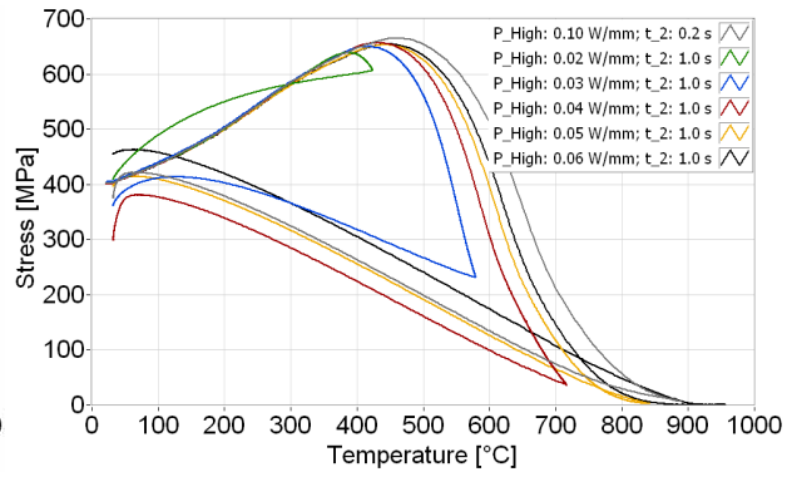

d)

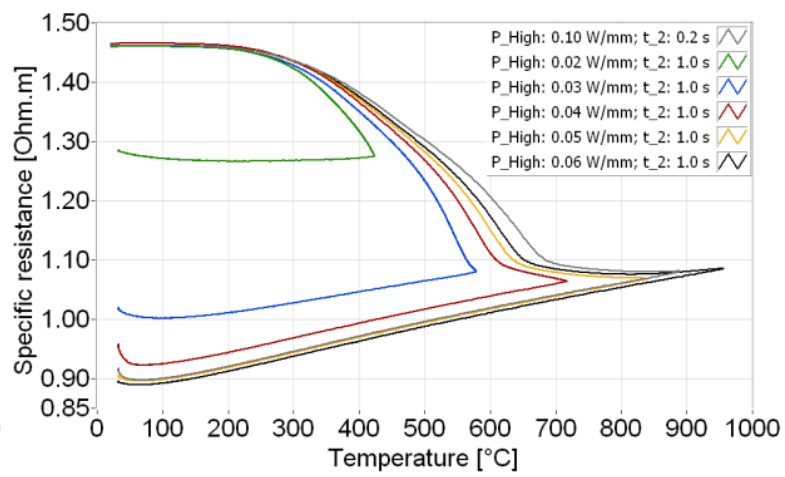

Fig. 4. Comparison of the evolution of tensile stress and electrical resistivity of the as drawn NiTi wires with time and temperature measured in FTMT-EC treatments with maximum power $\mathrm{P}=2,3,4,5,6 / 1 \mathrm{~s}$ and $10 \mathrm{~W} / 0.2 \mathrm{~s}$.

\section{Heat treatment of continuous filaments during respooling}

In order to be able to perform FTMT-EC treatment on kilometers of continuous thin NiTi filaments for textile applications, a prototype of dedicated equipment called NITITEC (Fig. 5) was designed and built. The wire is treated during respooling while passing over two electrodes [9]. Electric power, wire speed and wire tension are the key process parameters. Temperature between the electrodes and electrical resistance of the treated wire when it cools down are monitored (see Fig. 5) and used as feedback signals in process control.

\section{Conclusions}

A FTMT-EC method for thermomechanical treatment of thin NiTi filaments by electric current has been presented. Main differences compared to the conventional heat treatments of NiTi wires in a furnace are as follows:

i) heat comes from inside the material,

ii) possible actions of electrons on recovery processes can not be excluded,

iii) heat treatment can be performed extremely fast,

iv) maximum temperatures in the practical treatments reach $\sim 1000^{\circ} \mathrm{C}$,

v) temperature profile $\mathrm{T}(\mathrm{t})$ characterizing the treatment conditions is precisely controlled during the temperature increase,

vi) stress profile $\sigma(t)$ in the treated filament is either known or controlled,

Short NiTi wires having wide range of functional properties (particularly to transformation strain, hysteresis width, strength, cyclic stability of superelastic NiTi wires) were prepared by the pulsed FTMT-EC treatment. The method of in-situ monitoring of electrical resistivity and tensile force during the heat treatment, which is a key to the FTMT-EC treatment since it provides indirect information on the recovery processes bringing about microstructure changes responsible for the functional property setting, was explained and discussed. 
Superelastic NiTi filaments were made by continuous FTMT-EC treatment of as drawn NiTi wire during respooling on a prototype of textile compatible equipment. Compared to the conventional straight annealing treatment applied for the same purpose by SMA producers, the FTMT-EC treatment is i) much faster (wire speeds as high as $10 \mathrm{~m} / \mathrm{s}$ are achievable), ii) more compact (the equipment is much smaller compared to $\sim 6 \mathrm{~m}$ long tubular annealing furnaces), iii) energy saving and iv) possibly allows to achieve filaments with different microstructures (functional properties). Since FTMT-EC treatment is less robust, it features an on line functional property output control (measurement of electric resistance of the wire after treatment). The FTMT-EC treatment process parameters $\mathrm{P}$, wire speed and wire tension can be on line updated based on the temperature and electric resistivity feedback signals.

\section{Acknowledgments}

The authors acknowledge the support of this work by EC within the integrated project AVALON (NMP2-CT-2005-515813) and support from the IP ASCR institutional project AV0Z10100520.

\section{References}

[1] K. Inaekyan, V Brailovski, S. Prokoshkin, A.Korotitskiy, A.Gletzer, J. Alloys and Compounds 473, 71(2009) [2] B.Malard, J.Pilch, P.Šittner V.Gartnerova, R. Delville, D. Schryvers and C. Curfs, Functional Materials Letters, 2, 1, (2009)

[3] R. Delville, B. Malard, J.Pilch, P.Šittner, D. Schryvers, in preparation

[4] B. Malard J.Pilch, P.Šittner, R. Delville, D. Schryvers and C. Curfs, in preparation

[5] A.R. Pelton, J. DiCello, and S. Miyazaki, in SMST-2000: Proceedings of the International Conference on Shape Memory and Superelastic Technologies, eds. S.M. Russell and A.R. Pelton, Pacific Grove, California.

[6] T.W. Duerig, K.N. Melton, D. Stöckel, and C.M. Wayman, eds., Engineering Aspects of Shape Memory Alloys (Butterworth-Heinemann Ltd., London), 1990.

[7] D. Favier, L. Orgeas, D. Ferrier, P. Poncin, Y. Liu. Journal de Physique IV France, 11541 (2001)

[8] P. Šittner, V. Novák, L. Heller, P. Sedlák, M. Landa and J. Van Humbeeck, SMST 2006, Asilomar, USA, 2008, p. 553-568

[9] Czech patent application PV2009-279

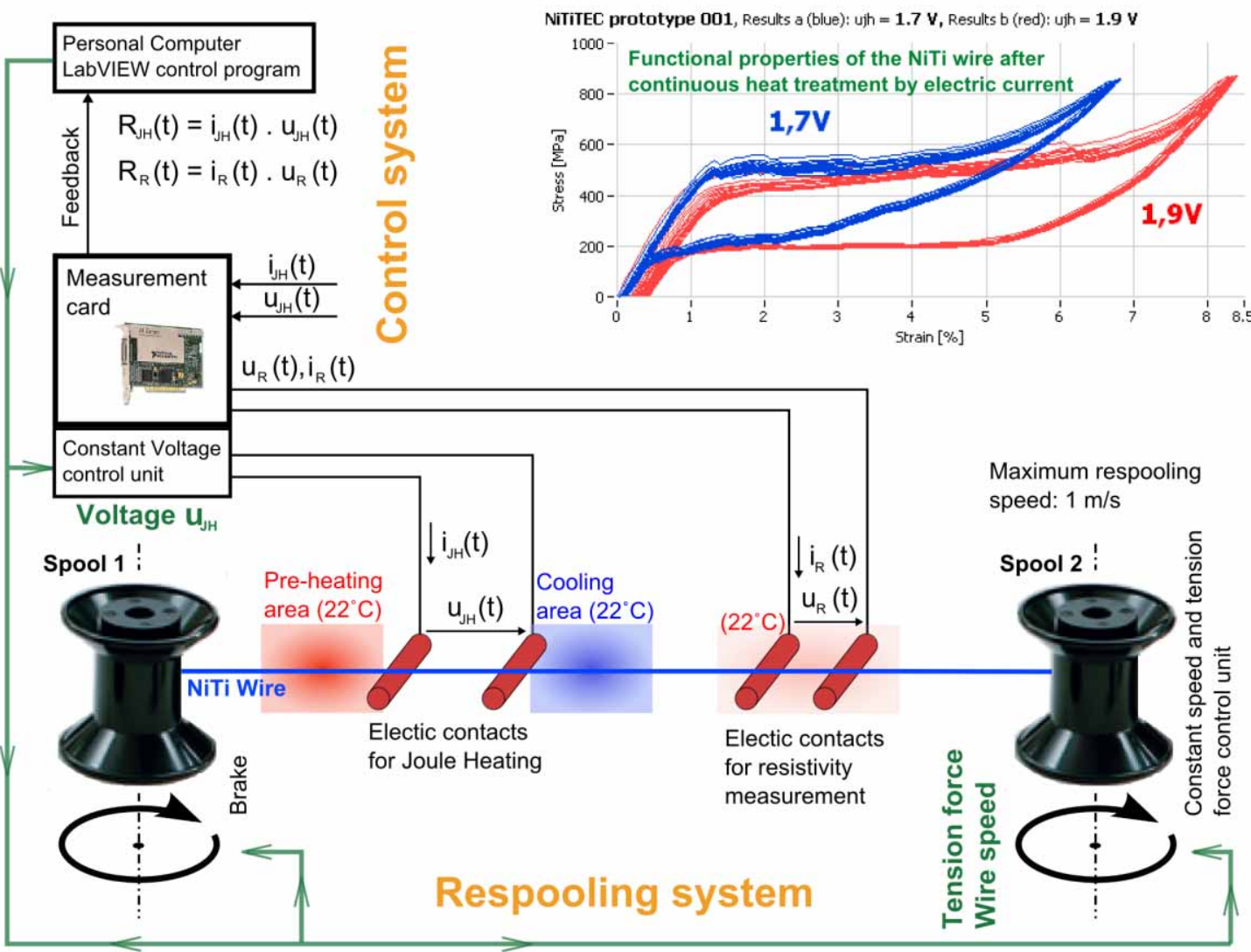

Fig. 5. Scheme of the NITITEC equipment for FTMT-EC treatment of continuous thin NiTi filaments for textile applications. 